\title{
ESTRATÉGIAS DE PROMOÇÃO DE VENDAS EM CONCESSIONÁRIAS DE AUTOMÓVEIS
}

\author{
STRATEGIES FOR PROMOTING SALES IN CAR DEALERS
}

\author{
Michele Raasch \\ Universidade Federal de Santa Catarina, Florianópolis, SC, Brasil. E-mail: micheleraasch@hotmail.com \\ Joáo Henriques de Sousa Júnior \\ Universidade de Passo Fundo, Passo Fundo, RS, Brasil. E-mail: sousajunioreu@hotmail.com
}

DOI: http://dx.doi.org/10.31512/gesto.v9i2.285 Recebido em: 04/12/2020

Aceito em: 04/05/2021

\begin{abstract}
Resumo: O processo de globalizaçáo auxiliou na internacionalizaçáo de alguns processos produtivos de empresas. Com isso, algumas organizaçôes, como as concessionárias de automóveis, terceirizaram processos como a comercialização do seu produto final. A promoção de vendas é um componente do mix de marketing que auxilia na venda dos produtos finais no curto prazo. O objetivo deste trabalho é verificar quais as estratégias de promoção de vendas utilizadas pelas concessionárias autorizadas, e de quem é a autonomia para realizar essas açóes. Para isto, foi realizado um estudo qualitativo, com a estratégia de estudo de caso e a utilização de entrevista semiestruturada. A amostra é composta por cinco concessionárias de automóveis de diferentes montadoras. Os resultados revelam que as concessionárias utilizam diferentes estratégias de promoção de vendas, cada uma com sua finalidade. A autonomia para realização das açóes de promoçáo de vendas pode ser da montadora, da concessionária, ou de ambas. Este estudo desenvolve a literatura e as pesquisas empíricas sobre as cadeias globais de valor e auxilia na compreensão do funcionamento da cadeia da indústria automobilística.
\end{abstract}

Palavras-chave: Cadeia Global de Valor. Promoção de Vendas. Mix de Marketing. Indústria Automotiva.

\begin{abstract}
The globalization process helped in the internationalization of some companies' production processes. As a result, some organizations, such as car dealerships, have outsourced processes such as the marketing of their final product. Sales promotion is a component of the marketing mix that helps in selling the final products in the short term. The objective of this work is to verify which sales promotion strategies are used by authorized concessionaires, and whose autonomy is to carry out these actions. For this, a qualitative study was carried out, with the case study strategy and the use of semi-structured interviews. The sample consists of five car dealerships from different automakers. The results reveal that the concessionaires use different sales promotion strategies, each with its own purpose. The autonomy to carry out sales promotion actions can be the automaker, the concessionaire, or both. This study develops the literature and empirical research on global value chains and assists in understanding the functioning of the auto industry chain.
\end{abstract}

Keywords: Global Value Chain. Sales promotion. Marketing Mix. Automotive industry. 


\section{INTRODUÇÃO}

O processo de globalização afetou diretamente o progresso tecnológico, a desregulamentação do mercado, entre outros eventos que levaram a uma mudança no comportamento de algumas organizaçóes. Este processo surgiu ao longo das últimas décadas do século XX e se caracterizou pela intensidade e pela abrangência dos seus efeitos que envolveram todos os países em diferentes esferas, como a política, social, cultural e econômica. (WALLERSTEIN, 1979; ALMEIDA; LINS; CATELA, 2020).

É nesse movimento de globalização que a internacionalização da produção emerge como estratégia capitalista, expandindo as empresas transnacionais que se beneficiaram dessa terceirização, reduzindo seus custos de produção e explorando a mão de obra em países em desenvolvimento. Campos (2019) afirma que a globalização divide-se em: financeira, produtiva e comercial; cada uma impactando em seus respectivos objetos. Com a globalização produtiva, surge a fragmentação produtiva, com processos divididos e terceirização, quebrando, assim, o padrão fordista de produção. A globalização e, como agente central, as empresas transnacionais, é que constituem a base da criação das Cadeias Globais de Valor (CGV) (CAMPOS, 2019).

As CGVs são cadeias nas quais diversos países produzem de forma fragmentada um produto; ou seja, cada país é responsável por uma etapa do processo de acordo com suas capacidades produtivas (ZHANG; SCHIMANSKI, 2014). O estudo sobre as CGVs busca explicar como ocorre o processo produtivo fragmentado em diversos países do mundo, integrando essas atividades e coordenando as fases do processo de produção (ARAÚJO, DIEGUES, 2021).

Ao longo dos anos 80 e 90, quando ocorreu o processo de reestruturação produtiva, as grandes empresas buscaram reduzir os seus custos e aumentar a sua flexibilização para obter vantagem frente ao forte mercado competitivo que se formava; foi entáo que o processo de fragmentaçáo produtiva expandiuse (HIRATUKA; SARTI, 2017). A partir de então, as empresas decidiram não mais produzir internamente certos produtos e passaram a realizar offshoring (terceirização) de algumas atividades e, até mesmo, o outsourcing (expatriação), tanto em nível nacional quanto em nível internacional (CAMPOS, 2019).

De acordo com o tipo de governança exercida, as CGVs podem se dividir em: cadeias comandadas por compradores, que são caracterizadas pelo domínio dos grandes varejistas dos países desenvolvidos, que terceirizam a sua produção em países em desenvolvimento e se concentram na comercialização; e cadeias comandadas por produtores, que são caracterizadas pelo domínio à jusante e à montante na cadeia das grandes empresas transnacionais (ZHANG; SCHIMANSKI, 2014).

A indústria automobilística é um exemplo de CGV comandada por produtores, na qual as montadoras fragmentam seu processo produtivo mundialmente. De acordo com Torres (2011, p. 22), "as empresas líderes na indústria automotiva se encarregam do design do produto, da produção da maioria dos motores e transmissóes e da montagem final dos veículos em suas plantas produtivas”. Pode-se considerar, ainda, que o bem final nessa cadeia não é apenas o automóvel em si, mas os demais serviços que o acompanham. Torres e Martins (2006) relatam que quando o indivíduo compra o automóvel, está comprando também os serviços de garantia, assistência técnica, entre outros.

Ao considerar que as CGVs incluem todo o processo produtivo, desde a fabricação até o pósvenda, e que o cliente, ao adquirir um automóvel, compra além do produto, consome também os serviços 
que o acompanham, percebe-se a dimensão da CGV do setor automotivo (TORRES; MARTINS, 2006). Dentro desse processo encontram-se as revendedoras autorizadas, que são o elo da cadeia responsável por comercializar e prestar o serviço do pós-venda. Nesse processo de comercializaçáo existem os procedimentos de promoção de vendas, que são responsáveis por auxiliar na venda imediata dos veículos.

As redes de concessionárias autorizadas são o canal de distribuição das montadoras, responsáveis pela oferta de veículos ao consumidor; são, portanto, a principal via de venda dos veículos produzidos ao longo da cadeia (COSTA; HENKIN, 2016). Porém, Costa e Henkin (2016) salientam que essas empresas seguem os padróes e as políticas postuladas pelas montadoras, influenciam tanto no preço dos veículos quanto nas estratégias de vendas.

Conforme Carvalho (2005), as revendedoras seguem as estratégias regidas pela matriz/montadora. Nesse sentido, Nepomuceno et al. (2016) informam que a Associação Brasileira de Marketing Direto (ABEMD) relatou que as concessionárias e suas respectivas montadoras trabalham duro para atrair e fidelizar seus clientes, ganhando vantagem aqueles que melhor identificarem as reais necessidades e desejos de seus clientes-alvo.

Assim, utilizando-se do argumento de Ladeira e Santini (2018), que afirmam que onde existe comércio existe também a promoçáo de vendas, uma vez que esta possui objetivos que podem gerar vantagem mercadológica para as empresas. Então, podemos considerar que o serviço prestado pelas concessionárias faz uso de todos os 4P's que compóem o mix de marketing, incluindo a promoção que é o foco da pesquisa. Vale ressaltar que esta pesquisa visa, então, analisar a cadeia de valor automotiva através da teoria do mix de marketing com foco na promoção de vendas, cujo intuito é incentivar a rápida comercialização dos produtos, com incentivos de curto prazo, incluindo propagandas e promoçôes.

A escolha de um único item do composto de marketing, a promoção de vendas ocorre pela inquietação sobre quem é responsável pelas estratégias de promoção de vendas, são as montadoras que determinam as estratégias? Ou as concessionárias possuem autonomia para realizar tais estratégias de acordo com seu contexto? De forma a aprofundar o conhecimento específico deste composto que possui grande relevância para a venda imediata dos veículos, com a utilização de suas variadas formas de comunicação. Com isso será possível identificar a dependência das concessionárias, neste composto, para com as montadoras nesta cadeia global de valor.

Nesse sentido, frente a todo o exposto, o presente trabalho tem por objetivo verificar quais são as estratégias de promoçáa de vendas utilizadas pelas concessionárias autorizadas de automóveis das cidades de Florianópolis/SC e Pelotas/RS, e quem possui autonomia para realizar essas estratégias.

\section{CADEIAS GLOBAIS DE VALOR}

Os estudos acerca das CGVs iniciaram ao final da década de 70, com a denominada "Teoria do Sistema-Mundo", de Terrence Hopkins e Immanuel Wallerstein, que inicialmente denominaram as cadeias de valor como "commodity chains", a qual foi utilizada também para explicar a desigualdade existente entre as naçôes (CAMPOS, 2019). No ano 2000, o termo "Cadeias Globais de Valor" surge em uma reunião entre estudiosos da globalização econômica na Itália (CAMPOS, 2019). 
As CVGs podem ser entendidas como "um conjunto de atividades desenvolvidas pelos funcionários e pelas firmas para produzirem um produto, desde sua concepção até o uso final”, com uma estrutura de coordenação por meio da governança (CAMPOS, 2019, p. 15). Os autores Gereffi e Fernandez-Stark (2011) salientam que as CGVs abrangem de forma completa o processo produtivo, da pré-produçáo até o pós-venda. Segundo pesquisa de Timmer et al. (2014), as empresas fragmentam as atividades produtivas as quais possuem um trabalho de baixa qualificação e de baixo valor agregado.

Conforme Almeida, Lins e Catela (2020), é crescente o interesse pelo debate sobre CVGs, sobretudo com respeito às possibilidades dos países que adentram a órbita dessas estruturas. Tal feito pode ser considerado, ainda de acordo com estes autores, pelo crescente interesse e publicação de diversos estudos contemporâneos sobre o comércio baseado na distribuiçáo internacional de atividades produtivas, o que remete às CVGs.

As CGVs podem ser diferenciadas de acordo com o tipo de governança, existem as cadeias comandadas pelo produtor, em que grandes empresas, geralmente transnacionais, desempenham o papel da coordenação, inclui-se aqui indústrias de computadores, de máquinas pesadas, de automóveis e as cadeias comandadas por compradores, em que grandes varejistas coordenam a cadeia, terceirizando a produção de calçados, brinquedos, eletrônicos e gerenciando apenas as vendas e a marca (GEREFFI, 1999).

A inserção de países em desenvolvimento nas CGVs traz uma série de benefícios, como investimentos, aprendizado, inovação e, por consequência, o upgrading econômico. Essa inserção pode ser considerada o primeiro passo para o acesso a novos mercados e a novas fontes de conhecimento e tecnologia, porém os países em desenvolvimento ainda participam em menor grau das CGVs (CAMPOS, 2019). É o caso do Brasil, que não aprofundou a intensidade tecnológica de suas exportações (REIS; ALMEIDA, 2014; IEDI 2013; 2016).

\subsection{Indústria Automobilística e a Cadeia Global de Valor}

A indústria automobilística pode ser considerada uma cadeia produtiva liderada por produtores, visto que, segundo Humphrey e Schmitz (2001, p.7), nelas "os parâmetros chave são estabelecidos por empresas que controlam tecnologias chave de produto e de processo". Alguns fatores contribuíram para que a produção de automóveis esteja espalhada por diversos locais, como a saturação do mercado e as pressóes políticas para produzir no país de venda (LIMA, 2014).

Por volta das décadas de 1980 e 1990, o processo de transição das indústrias automobilísticas começou a tomar novos rumos e expandir-se de indústria nacional para indústria globalmente integrada (LIMA, 2014). Nesse período que algumas montadoras da América do Norte e da Europa Ocidental reduziram sua produção nacional e começaram a transferir alguns processos para seus fornecedores (LIMA, 2014).

A indústria automotiva inserida na CGV é uma organização que se caracteriza pelo seu "investimento estrangeiro direto, pela produção de "modelos globais" e pelo comércio internacional de veículos e autopeças" (TORRES, 2011, p. 23). Essa inserção apresentou três aspectos comuns entre as montadoras: i) produzir onde se vende; ii) o desenho de veículos com plataformas que se adaptem a 
diferentes acabamentos de adaptação ao mercado; e iii) o aproveitamento das plataformas globais para criar capacidade de montagem mais genérica e menos presa a modelos específicos, buscando a flexibilidade de suas plantas (LIMA, 2014).

As montadoras de automóveis responderam à globalização através de três elementos destacados por Mesquita et al. (2013), que são: a padronização, a simplificação e a terceirização. As empresas líderes da indústria automobilística "exigem que seus principais fornecedores tenham uma presença global[...], já que os veículos concebidos na matriz são fabricados em várias regiôes” (LIMA, 2014, p. 40).

O Regime Automotivo Brasileiro, adotado pelo governo brasileiro em 1995 e esteve em vigor até 1998, permitiu a expansão da indústria automobilística no país em busca da retomada de investimentos e do aumento das exportaçóes (MESQUITA et al., 2013), o que permitiu a modernização e reestruturação da cadeia produtiva desta indústria (TORRES; CARIO, 2013).

Após a crise no setor automotivo, é a partir de 2004 que ele volta a expandir-se por conta de diversos fatores como o crescimento sustentado da economia, a reduçáo da taxa de juros e o aumento do mercado interno (MESQUITA et al., 2013). O governo cria o Novo Regime Automotivo Brasileiro, conhecido como Inovar-Auto, vigente de 2013 a 2017, com o intuito de melhorar a relaçáo do setor com o mercado internacional (MESQUITA et al., 2013).

A integração das filiais brasileiras de montadoras internacionais caracteriza-se pela perda da autonomia das filiais, pois elas ficam comprometidas pelas estratégias das matrizes (CARVALHO, 2005). Carvalho (2005) percebeu em seu estudo que as filiais brasileiras têm desenvolvido estratégias quanto à introdução de modelos de veículos que se adequem às características locais, com o desenvolvimento de plataformas específicas para países em desenvolvimento. Torres (2011) indica que a flexibilização das plantas produtivas em mercados emergentes permite aos fabricantes o ajuste da produção, conforme se identifique o crescimento do mercado e também as questóes de preferência dos consumidores, ou então as açôes de seus concorrentes.

Torres (2011) destaca em seu estudo que no Brasil existiram três momentos históricos sobre o ingresso de montadoras estrangeiras, são eles: década de 1920, pela inserção da GM e da Ford com a produção de ônibus e caminhóes; entre 1950 e 1980, com a instalação da Volkswagen, da Vemag, da Simca e da Fiat, produzindo veículos de passeio (produçáo adotada mais tarde também pela GM e pela Ford); década de 1990, quando ocorreu a abertura da economia brasileira, o Regime Automotivo Brasileiro adotado pelo governo, nesse período instalaram-se no país a Renault, a Peugeot-Citroën e a Toyota. Esses três momentos marcaram a ampliação e a modernização da produção automotiva nacional.

O Brasil foi o nono maior produtor de veículos no ano de 2005, resultado superado em 2008 quando se torna o sexto maior produtor (TORRES, 2011). Segundo os dados do levantamento realizado pela Associação Nacional dos Fabricantes de Veículos Automotores - ANFAVEA, em 2017, o Brasil foi o segundo maior país da América Latina produtor de automóveis, atrás do México, e faturou naquele ano US\$ 52.221 milhões (ANFAVEA, 2019). 


\subsection{Brasil: Integração na Cadeia Global de Valor}

Entre 1995 e 2011, o Brasil avançou na participação nas GVCs, mas esta participação ainda foi baixa em comparação com outros países, por conta de alguns fatores como a disponibilidade de matériasprimas e a composição setorial da indústria (IEDI, 2016). Outro fator que explica esse baixo envolvimento é o investimento realizado pelo Brasil, uma vez que o investimento é essencial na CGV. O Brasil, quanto ao Investimento Estrangeiro Direto (IED), não se encontra entre os 20 maiores investidores mundiais, apesar de estar entre as 10 maiores economias do mundo. Para mudar esta situação, políticas econômicas são necessárias, conforme Reis e Almeida (2014).

O Brasil não está totalmente fora das CGVs, mas seu lugar é mais como fornecedor de insumos para empresas de outras origens adicionarem mais valor na cadeia produtiva, do que como exportador de produtos com maior valor adicionado. Além disso, as empresas multinacionais têm cada vez mais buscado o mercado brasileiro e o latino, atraídas pelo mercado interno ou a exploração de recursos naturais (REIS; ALMEIDA, 2014, p. 25).

O Instituto de Estudos para o Desenvolvimento Industrial (IEDI) desenvolveu algumas cartas que tratam do Brasil em relação às CGVs. A Carta IEDI n 597/2013 abordou o descompasso do Brasil em relação ao IED e a sua participação nas CGVs. Esta carta ainda destaca que uma maior participação nas CGVs possui relaçáo positiva com maiores taxas de crescimento do PIB, o que não é visto no Brasil. A Carta IEDI n 597/2013 relata que o Brasil possui uma frágil participação nas CGVs e, também, baixos níveis tecnológicos, impactando em sua produtividade.

A Carta $n^{\circ} 734 / 2016$ do IEDI relatou que a participação do Brasil nas CGVs avançou de forma insuficiente, apesar de apresentar indicadores de engajamento positivos. Por esses motivos, as cartas mostram que o Brasil ainda é um país que dentro das CGVs se concentra em atividades menos tecnológicas, de menor valor agregado, o que leva o país a ter uma baixa inserção nas CGVs. É necessário compreender, ainda, que no período atual, de intensa competitividade e marcada fragmentação produtiva internacional, “a participação de países menos desenvolvidos em CGV pode lhes representar uma expansão industrial mais acelerada e facilmente atingida" (ALMEIDA; LINS; CATELA, 2020).

\section{MIX DE MARKETING}

O marketing é definido pela American Marketing Association (AMA, 2017) como uma atividade ou um conjunto de instituiçóes e processos que visam criar, comunicar, entregar e trocar ofertas que têm valor para os consumidores, clientes, parceiros e sociedade em geral. Assim, de acordo com Fonseca (2013, p. 10), as empresas devem "elaborar uma estratégia para comunicar o produto ofertado ao cliente, de forma que crie uma sensação de necessidade e desejo do cliente pelo produto".

Inicialmente, compreende-se a necessidade de buscar definiçóes para o marketing. Segundo Kotler e Keller (2012, p. 4), o marketing compreende "um processo pelo qual indivíduos e grupos obtêm o que necessitam e desejam por meio da criação, da oferta e da livre troca de produtos de valor entre si”. Do ponto de vista de Flores (2018), o marketing é o que direciona a organização, pois é ele que possibilita o conhecimento quanto às necessidades dos clientes, reconhece o público-alvo da organização com o objetivo de satisfazer seus desejos, além de fidelizar clientes e trazer lucro para organização. 
Jerome McCarthy, na década de 1960, refinou a ideia de mix de marketing apresentado por Borden, que era composta por 12 elementos: planejamento de produtos; preço; gestão da marca; canais de distribuição; vendas; publicidade; promoção; embalagem; exibição; manutenção; manuseio; análise de fatos (GOI, 2009).

Na verdade, o que McCarthy fez foi reagrupar os doze elementos propostos por Borden em uma versão mais sintetizada, cujo resumo tornou-a mais objetiva (GOI, 2009). Essa versão é a mais conhecida nos dias atuais. Ela é constituída por quatro dimensões, os 4P’s de Produto, Preço, Praça e Promoção, que foi popularizado por Philip Kotler, durante a década de 1990 (BIAZUS, 2015). Kotler (1998, p. 97) define o mix de marketing como "o conjunto de ferramentas que a empresa usa para atingir seus objetivos de marketing no mercado-alvo".

A definição de cada um dos elementos do mix de marketing é abordada por Kotler (2000) como: Produto se refere a "algo que pode ser oferecido a um mercado para satisfazer uma necessidade ou desejo" (KOTLER, 2000, p. 416); Preço é o único "elemento do mix de marketing que produz receita" (KOTLER, 2000, p. 476); Praça é o canal de distribuição, o ponto de venda; Promoção é a comunicação da indústria para o consumidor sobre o produto através da comunicação (KOTLER, 2000). No setor automotivo, a Praça é a concessionária, é o meio através do qual o Produto chega ao consumidor (FONSECA, 2013).

O autor Honorato (2004) realiza uma uniáo entre os elementos, na qual para ele os produtos precisam atender às necessidades dos clientes, e devem estar disponíveis aos consumidores por meio do canal de distribuição. Segundo o autor, para que o consumo aconteça, é necessário desenvolver estímulos nos consumidores através da promoçáo e do preço, duas estratégias de venda decisivas.

De acordo com Kotler (2000, p. 401),

Empresas internacionais devem decidir até que ponto adaptarão suas estratégias de marketing às condiçóes locais [...] temos empresas que utilizam um mix de marketing padronizado globalmente. A padronização do produto, da propaganda e dos canais de distribuição permitem custos mais baixos. No outro, temos um mix de marketing adaptado, em que a empresa adapta elementos do mix de marketing para cada mercadoalvo.

Sendo assim, as açóes de marketing auxiliam no consumo de produtos, uma vez que elas são responsáveis pelo incentivo e pela persuasão aos consumidores (HONORATO, 2004). O mix de marketing é uma ferramenta que permite a visualização do trabalho do gestor de marketing, bem como onde este aloca os recursos destinados ao setor (GOI, 2009).

\subsection{Promoção de Vendas}

A promoção de vendas caracteriza-se por diferentes tipos de incentivos de experimentação ou de compra, de curta duração, tais como: cupons, concursos e prêmios (KOTLER; KELLER, 2012). Ela age no curto prazo, estimulando o consumo imediato, na qual a vantagem - desconto, cupom, brinde - é percebida pelo cliente no ato da compra (LADEIRA; SANTINI, 2018). Também é definida como qualquer atividade de comunicação promovida pela empresa, utilizada para promover o produto e fazer com que o consumidor perceba a existência deste para atender às suas necessidades e desejos (FLORES, 2018). 
Definição semelhante a dos autores Ladeira e Santini (2018), que consideram a promoção de vendas como um conjunto de ferramentas utilizado para promover o consumo imediato no curto prazo. Os autores ainda explicam que,

Dentro do composto de marketing, a promoção é utilizada como uma ferramenta que tem o objetivo de comunicar e persuadir os consumidores dos benefícios de um produto. Nesse sentido, a promoção informa e lembra os compradores das características básicas dos produtos ofertados. (LADEIRA; SANTINI, 2018, p. 88).

São ferramentas da promoção de vendas: amostras, cupons, descontos, brindes, experimentação gratuita, garantias, promoções combinadas e cruzadas, feiras e exposições (KOTLER; KELLER, 2012). Elas são capazes de apresentar aos clientes novas possibilidades de experiências (LADEIRA; SANTINI, 2018).

Os incentivos realizados em forma de promoçôes são ofertados com o objetivo de conquistar novos clientes, fidelizar os antigos, elevar a taxa de recompra, e ainda servem como uma forma do cliente experimentar a marca/produto (KOTLER; KELLER, 2012). Este conjunto de ferramentas que compõe a promoção possui objetivos que podem gerar vantagem mercadológica para as empresas (LADEIRA; SANTINI, 2018). Estes objetivos podem ser estratégicos, como: gerar lealdade, aumentar a competitividade em mercados turbulentos e conectar os setores da empresa; ou objetivos operacionais, como: acelerar as vendas, desovar os estoques, criar uma razão para o consumo (LADEIRA; SANTINI, 2018).

$\mathrm{Na}$ indústria automobilística, utiliza-se das promoçóes do fabricante, que são descontos e brindes que buscam incentivar os test-drives e as compras, outra estratégia de incentivo utilizada por este setor é o abatimento em dinheiro. Kotler e Keller (2012) destacam algumas estratégias da promoção, como: propaganda; promoçôes; relaçôes públicas; vendas pessoais; marketing direto; patrocínio. Kotler e Keller (2012) apresentam a distinção entre propaganda e promoção de vendas, segundo os autores a primeira seria a razáo para a compra e a segunda o incentivo.

A propaganda caracteriza-se como qualquer tipo de apresentação e promoção pagas, possíveis em diversos meios de comunicação, com alcance geográfico para diversos consumidores (KOTLER; KELLER, 2012). De acordo com Fonseca (2013), ela é uma forma de persuadir o cliente a desejar o produto ofertado. Para Kotler e Keller (2012), a propaganda serve tanto para criar vínculo com o consumidor quanto para estimular vendas rápidas.

Quanto às promoçóes, estas podem ser em forma de descontos, pacotes de bônus, dois pelo preço de um, amostra grátis, cupons, cartóes de fidelidade, prêmios, descontos por quantidades adquiridas, concursos, subsídios e quaisquer outras 'ofertas' que a empresa desejar. As vendas pessoais são flexíveis, ajustam-se a cada situação específica, é, ainda, capaz de construir um relacionamento com o cliente; as relaçôes públicas são formas de interação entre a organização e o cliente; o marketing direto é um serviço personalizado e bem segmentado para o consumidor-alvo (HOOLEY; PIERCY; NICOULAUD, 2011). Cabe salientar que Nepomuceno et al. (2016) consideram o marketing direto um impulsionador no setor automotivo, com o uso de e-mail, mala-direta, telemarketing.

A promoção de vendas pode ser classificada quanto: i) à natureza, que relaciona-se com os benefícios percebidos pelos clientes, divide-se em monetária ou não monetária; ii) aos efeitos perceptuais, que podem ser econômicos, informacionais ou psicológicos; iii) aos propósitos e público-alvo, se para 
varejistas, comércio ou consumidores; iv) aos efeitos de tempo, que podem ser imediatos, de ajuste ou permanentes; v) aos tipos de compra que são estimulados, os quais podem ser de compra por categoria, de escolhas de uma marca ou de compra por quantidade (LADEIRA; SANTINI, 2018).

\section{METODOLOGIA}

Este estudo caracteriza-se como qualitativo, uma vez que busca evidenciar resultados não alcançados através de métodos estatísticos ou outros meios de quantificação (STRAUSS; CORBIN, 2008); e utiliza como estratégia de pesquisa o estudo de caso, por compreender que tal estratégia permite a composição de um estudo mais robusto, uma vez que pode-se coletar dados com maior riqueza de informaçóes e análises, em função da solidez dos resultados (YIN, 2015). Os critérios de seleção dos respondentes foram não probabilísticos e por conveniência. Ainda, o presente estudo segue o processo de documentaçáo de dados proposto por Flick (2009, p. 265), qual seja o de "gravação dos dados, edição dos dados (transcrição) e a construção de uma 'nova' realidade no texto produzido e por meio dele".

Esclarecidos os pontos que norteiam a pesquisa, é salutar indicar que os dados foram coletados através de entrevistas semiestruturadas, que aconteceram por meio de contato direto com o entrevistado, contato telefônico, ou ainda de forma assíncrona online, conforme orientação de Flick (2009). Foram coletados também através da observação de materiais audiovisuais e documentos qualitativos, textos e imagens de site e redes sociais, conforme orientação de Creswell (2010). As entrevistas pessoais foram gravadas com a autorização do entrevistado. Nas entrevistas via telefone, foram transcritas no ato as informaçóes consideradas relevantes para o questionamento realizado.

A análise dos dados iniciou com a transcrição das entrevistas e posterior categorização das respostas em geral, de acordo com as variáveis, baseadas na literatura sobre o mix de marketing, consideradas para a elaboração do formulário semiestruturado da entrevista. Posteriormente, foi realizada a análise qualitativa de conteúdo através da exposição, da redução e da estruturação da análise (FLICK, 2009). Os dados são apresentados com auxílio da interação da fala dos entrevistados e também com o uso da análise comparativa dos casos entre si (FLICK, 2009) e dos dados apresentados na literatura existente.

Para a formulação do formulário de entrevista semiestruturado, foi visitada a literatura a respeito do mix de marketing, especificamente a promoção e vendas. O Quadro 1 apresenta as variáveis e seus respectivos autores. 
Revista GESTO: Revista de Gestão Estratégica de Organizaçôes

Santo Ângelo | v. 9 | n. 2 | p. 135-154 | jul./dez. 2021 | DOI: http://dx.doi.org/10.31512/gesto.v9i2.285

Quadro 1 - Variáveis e autores utilizados no questionário semiestruturado

\begin{tabular}{|c|c|c|c|}
\hline Variável & Autor & Variável & Autor \\
\hline Desconto & $\begin{array}{l}\text { Biazus (2015); Ladeira e Santini } \\
\text { (2018) }\end{array}$ & Promoção & $\begin{array}{l}\text { Biazus (2015); Ladeira e Santini } \\
(2018)\end{array}$ \\
\hline Canais de mídia & $\begin{array}{l}\text { Biazus (2015); Nepomuceno et al. } \\
\text { (2016) }\end{array}$ & Propaganda & Biazus (2015) \\
\hline Marketing Direto & Biazus (2015) & $\begin{array}{l}\text { Slogan "dos } \\
\text { sonhos" }\end{array}$ & Ladeira e Santini (2018) \\
\hline Fidelidade & $\begin{array}{l}\text { Nepomuceno et al. (2016); Ladeira e } \\
\text { Santini (2018) }\end{array}$ & \multirow{3}{*}{$\begin{array}{c}\text { Ação de } \\
\text { promoção (ex.: } \\
\text { comprou ganhou) }\end{array}$} & \multirow[t]{3}{*}{ Ladeira e Santini (2018) } \\
\hline Brinde & Ladeira e Santini (2018) & & \\
\hline Cupom Desconto & $\begin{array}{l}\text { Nepomuceno et al. (2016); Ladeira e } \\
\text { Santini (2018) }\end{array}$ & & \\
\hline
\end{tabular}

Fonte: Autoria própria (2021).

Participaram da pesquisa três concessionárias autorizadas de veículos da cidade de Florianópolis/ SC e duas da cidade de Pelotas/RS. Por solicitação das mesmas, seus nomes/marcas não serão divulgados, apenas uma delas autorizou a divulgação, porém decidiu-se por padronizar a não apresentação deste dado. Pode-se afirmar que as cinco concessionárias participantes são de montadoras distintas.

Primeiramente, na cidade de Florianópolis/SC, ocorreu contato telefônico com nove concessionárias autorizadas, em que três prontificaram-se a colaborar com a pesquisa. Foram realizados novos contatos com as demais seis concessionárias, que não manifestaram interesse em participar da pesquisa. $\mathrm{Na}$ cidade de Pelotas/RS, foram contatadas três concessionárias autorizadas de veículos, duas delas demonstraram interesse em participar da pesquisa.

Posteriormente, verificou-se com o gestor de vendas e/ou marketing a melhor forma para entrevista e foi verificada a que melhor se encaixava na agenda dos entrevistados e entrevistador. O procedimento de coleta, desde o primeiro contato, iniciou-se em novembro de 2019 e finalizou em dezembro de 2019. Neste trabalho vamos nomear as concessionárias com a abreviação Concessionária Autorizada de Veículos (CAV), desta forma: CAV1, CAV2, CAV3, CAV4, CAV5.

\section{ANÁLISE DOS DADOS}

Após a transcrição dos dados, estes foram categorizados de acordo com as variáveis utilizadas para a formulação do questionário semiestruturado. Os dados encontrados serão discutidos nesta seção e relacionados com a literatura existente a respeito da promoção de vendas.

Primeiramente são descritos os dados demográficos dos gestores que participaram das entrevistas. A entrevistada da CAV1, do sexo feminino, há dois anos é encarregada do setor de marketing da concessionária. Possui ensino médio completo e sua faixa etária varia de 26 a 40 anos. A entrevistada da CAV2, também do sexo feminino, há quatro anos é gestora financeira da concessionária. Possui ensino médio completo e está na faixa etária de 26 a 40 anos. 
O entrevistado da CAV3, do sexo masculino, encontra-se na faixa etária de 26 a 40 anos. Possui ensino médio completo e há quatro anos é gerente de vendas da concessionária. O entrevistado da CAV4, do sexo masculino, há dez anos é gerente de vendas da concessionária. Possui ensino médio completo e está na faixa etária de 41 a 60 anos. O entrevistado CAV5, do sexo masculino, é gerente comercial na empresa há dez anos. Possui ensino superior completo e está na faixa etária de 26 a 40 anos.

Antes de procurar compreender a promoção de vendas do mix de marketing desenvolvido por cada empresa, foram realizadas perguntas quanto às estratégias de adequaçáo de preço, baseado em Kotler e Keller (2012). Quanto a este aspecto, todas as concessionárias confirmaram praticar a estratégia de preço geográfico e de preço discriminatório, venda de um produto por dois ou mais valores distintos em que não há diferença significativa nos custos de produção do mesmo (KOTLER; KELLER, 2012).

$\mathrm{Na}$ pesquisa desenvolvida por Biazus (2015), em uma revendedora de carros da cidade de Chapecó/SC, a pesquisadora identificou que a empresa não aplicava o preço geográfico, mas sim o preço discriminatório, dependendo do volume de vendas, da versão do veículo e da época do ano, semelhante ao que foi encontrado nesta pesquisa com concessionárias autorizadas. Portanto, a estratégia da revenda é semelhante à da concessionária autorizada.

Quatro das concessionárias estudadas ajustam seus preços de acordo com a localização, o tipo de produto para determinados segmentos de clientes, a versão do produto, o nível de exigência, o volume de compra e o período de compra. O gestor da CAV3 explica "[...] normalmente segue o padráo do preço público sugerido pela montadora no site oficial [...] o preço é variável de acordo com o tipo de compra [...]”. A concessionária CAV5 não realiza a prática do preço discriminatório, apenas do preço geográfico, de acordo com o gestor "pode variar de acordo com a região e a necessidade. "

Outra estratégia de preço considerada importante neste estudo foi a oferta de descontos, quanto a isso Kotler e Keller (2012, p. 433) alertam "caso se espalhe a notícia de que o preço de tabela da empresa é "flexível” e dar descontos é a regra, a percepção de valor das ofertas será minada. ”

Todas as concessionárias participantes da pesquisa trabalham com descontos, que variam de acordo com a condição de pagamento (CAV1, CAV2), o tipo de cliente e se o cliente é pessoa física ou pessoa jurídica (CAV3, CAV4). Alguns descontos são divulgados nas mídias (CAV1, CAV2, CAV3), outros ofertados no momento da compra (CAV3, CAV4), "de acordo com a necessidade de fechar a venda" (CAV3). Também são ofertados quando a concessionária sente "a necessidade de fazer volume para atingir os objetivos (CAV5). ” Ainda "quando se está com baixo faturamento" (CAV1), descontos também são ofertados em datas comemorativas (CAV1).

Os gestores possuem autonomia para conceder os descontos, alguns são impulsionados pelas montadoras. O gestor da CAV5 explica que a concessionária é responsável por autorizar os descontos, porém "seguimos uma política comercial sugerida pela fabricante". Resultados que corroboram com os achados de Biazus (2015), na revenda de automóveis, nos quais os descontos são aplicados de acordo com a forma de pagamento, o modelo do veículo, se fora de linha ou não, e o tempo em que o veículo está estocado.

Partindo para a análise que visa responder ao objetivo proposto na pesquisa, inicia-se a verificação da variável propaganda. As concessionárias realizam propagandas nos seguintes canais: Televisão (CAV3, 
CAV4, CAV5), rádio (CAV1, CAV2, CAV3, CAV4), jornais (CAV4, CAV5), impressa via folderlfyers (CAV1, CAV3, CAV4, CAV5), redes sociais (CAV1, CAV2, CAV3, CAV5), mensagem no celular (CAV1) e e-mail de marketing (CAV1, CAV2).

Algumas vantagens sobre cada canal de mídia são apresentadas por Kotler e Keller (2012, p. 550), como: jornais: flexibilidade, boa cobertura de mercado local; televisão: combinação de visão, som e movimento, alto nível de atenção, ampla cobertura; rádio: uso em massa, alto grau de seletividade geográfica e demográfica, baixo custo; folhetos: flexibilidade, controle total, mensagens de maior impacto; telefone: oportunidade de dar um toque pessoal; internet: alta seletividade, possibilidades interativas, custo relativamente baixo.

Algumas concessionárias pesquisadas por Fonseca (2013) também utilizam o rádio como forma de promoção; segundo o autor eram desenvolvidas açôes, chamadas "blitz" pela rádio, nas quais os clientes eram convidados a visitar a concessionária e, nos intervalos da programação, a rádio realizava "chamadas" para destacar as ofertas da empresa. Fonseca (2013) ainda destaca a relevância salientada pelos entrevistados sobre as promoçôes realizadas on-line, as concessionárias utilizam suas páginas nas redes sociais como forma de relaçôes públicas, elas servem como canal tanto de promoção quanto de ouvidoria.

Os autores Ladeira e Santini (2018) relatam que a forma das pessoas se comunicarem mudou, pois atualmente as comunidades on-line oferecem um meio simples de comunicação. Os autores ainda destacam que a promoção de vendas nas redes sociais possui como benefícios reforçar a "boca a boca" entre as pessoas de diversos locais, aproximar os consumidores da empresa e minimizar o atraso inovativo do mercado. Quatro das concessionárias pesquisadas ainda utilizam da rádio para realizar sua comunicação, o que mostra que nenhuma das opçóes deve ser descartada apesar da evolução no formato de comunicação.

Foram analisadas também as redes sociais e o site de cada uma das concessionárias entrevistadas. A CAV1 possui página no Facebook ativa e atualizada com frequência, nela estão as promoçóes de itens como pneus, serviços de troca de óleo e alguns lançamentos de veículos, divulgados de forma mais pessoal e interativa. As interaçôes realizadas através das promoçóes de vendas nas redes sociais são mais fortes que as realizadas no ambiente físico de varejo (LADEIRA; SANTINI, 2018). O site da concessionária é menos interativo, com anúncios dos carros que estão à venda e informaçôes dos serviços prestados. A CAV2 não possui conta própria em nenhuma rede social, existe uma conta do grupo regional no Facebook que divulga apenas informaçôes dos carros. Não existe site próprio também, somente há um site do grupo regional, em que são disponibilizadas informaçôes dos carros, produtos e serviços disponíveis.

A CAV3, semelhante à CAV2 não possui conta em nenhuma rede social, existe apenas uma conta no Facebook do grupo nacional, na qual são apresentados os veículos disponíveis nas concessionárias da marca, destaques para os detalhes dos veículos, anúncio de novas concessionárias; o site também é do grupo geral. A CAV4 possui página no Facebook ativa e atualizada, na qual são anunciadas as ofertas dos veículos, os detalhes dos carros, as feiras e as promoçóes monetárias. O site da concessionária possui informaçôes sobre os carros disponíveis e os serviços prestados, porém é menos pessoal e mais informativo, diferente da página na rede social que, além de informativa, possui aspecto pessoal em busca de um relacionamento com o cliente.

Por fim, a CAV5 possui conta no Facebook ativa e atualizada, na qual são postadas promoçóes de serviços, como troca de óleo, e venda de produtos, como pneus. Também são anunciadas feiras e 
campanhas, além de incentivar a experimentação dos carros através do test drive. O site da CAV5 é utilizado para apresentação dos modelos de carros disponíveis, informaçóes dos serviços prestados e venda direta. Ladeira e Santini (2018) salientam que as redes sociais são uma "ponte" para a visitação ao site da empresa, que possui informaçóes mais detalhadas sobre a mesma. De acordo com os apontamentos sobre a nova forma de comunicaçáo on-line, podemos perceber que as concessionárias pesquisadas estáo se inserindo neste formato, e possuem tendência em evoluir ainda mais nestas estratégias.

O gestor da CAV3 relata que a concessionária é responsável pelas propagandas realizadas, já a CAV2 e CAV4 relatam que a montadora é responsável pelas propagandas da concessionária. A gestora da CAV1 relata que a concessionária pode determinar as propagandas, sob pré-determinação da montadora. O gestor da CAV5 explica que a "montadora faz seu comercial em massa e a concessionária faz regional, de acordo com sua necessidade. " Portanto, a única concessionária que mostrou autonomia para realizaçáo de propagandas foi CAV3, as demais são dependentes da montadora (empresa líder).

De acordo com Humphrey e Shmitz (2001), as empresas líderes definem: i) o que deve ser produzido; ii) como deve ser produzido; iii) quando deve ser produzido; iv) quanto deve ser produzido; ev) a que preço deve ser produzido. Embora este último seja "normalmente" definido pelo mercado, acontece que clientes importantes pressionam seus fornecedores a produzir por um "preço-meta específico".

Quanto à realização de promoções, segundo (BIAZUS, 2015), elas englobam descontos, bônus, pague 2 e leve 1, cupons e fidelidade; portanto, todas essas variáveis serão abordadas neste tópico 'promoção'. Todas as concessionárias afirmam que trabalham com promoçôes, algumas direcionadas exclusivamente pela montadora (CAV2) e outras mais flexíveis entre a montadora e a concessionária, seguindo padróes da montadora (CAV1, CAV3, CAV4, CAV5). De acordo com CAV3 "algumas promoçôes são de nível nacional, nas quais acompanhamos o produto e o preço ofertado pela montadora, outras campanhas são locais, de ofertas de produtos que mais temos interesse em vender naquela ocasião. ” Na pesquisa de Pieritz (2007), as concessionárias pesquisadas da cidade de Blumenau demonstraram ter liberdade para tomada de decisão para promover as vendas, com utilização de promoçôes de sua responsabilidade.

O gestor da CAV5 destaca que existe diferença no canal através do qual a promoção é ofertada, para carros populares e para carros de luxo ou esportivos. O entrevistado CAV3 ainda destaca que há diferença na estratégia de venda entre os carros populares e os carros de luxo. Segundo o entrevistado, em carros populares o foco é em realizar parcelamento, já nos carros de luxo de marcas premium procura-se trabalhar o emocional, a qualidade e o acabamento do carro, e o "luxo de ter um carro daquela determinada marca". Quanto às marcas de luxo, premium, Kotler e Keller (2012) ressaltam que qualidade e exclusividade são itens primordiais no produto, e que os seus consumidores precisam sentir que aquele bem é especial.

A pesquisa de Fonseca (2013) identificou que estratégia semelhante para os modelos populares, de maior giro e maior estoque, eram utilizadas mídias de massa, em televisão, rádio e internet. De acordo com a pesquisa de Fonseca (2013, p. 22), a estratégia utilizada pelas concessionárias para este modelo de automóvel era "dar ênfase em taxas e preços atrativos de um modelo, para quando o cliente chegar à concessionária, o vendedor tentar convencê-lo a levar um modelo mais completo". Para os modelos premium não eram realizadas ações em massa, a estratégia utilizada neste caso era a demonstração in loco dos aspectos diferenciais do automóvel. Estas demonstraçôes ocorriam em locais de grande circulação de clientes potenciais (FONSECA, 2013). 
A técnica de promoção de vendas é utilizada como forma de incentivar a compra por impulso (LADEIRA; SANTINI, 2018). Elas são desenvolvidas pelas concessionárias pesquisadas de diferentes formas, são ofertadas aos clientes "de acordo com o volume de vendas (CAV4) ", sob responsabilidade do gestor de vendas da concessionária, ou então com frequência mensal pré-definida (CAV1, CAV2, CAV3, CAV5). O gestor da CAV3 destaca que,

a princípio são mensais, salvo algumas campanhas que podem também serem lançadas durante o mês [...] a responsabilidade de autorizar essas promoçôes é de ambas as partes, pois algumas sáo de nível nacional e outras são realizadas com participação financeira apenas da CAV3.

A promoção de vendas é dividida em monetária e não monetária. As monetárias englobam técnicas de descontos diretos, cupons de desconto, pague 1 leve 2, já as promoções não monetárias englobam brindes, experimentação, sorteios, comprou ganhou (LADEIRA; SANTINI, 2018).

Todas as concessionárias trabalham com a oferta de brindes e cupons de desconto, assim como no estudo de Fonseca (2013). Essas ferramentas ajudam a despertar o interesse temporário do consumidor, o que acaba por incentivar o consumo imediato (LADEIRA; SANTINI, 2018).

As concessionárias CAV1, CAV2, CAV5 não possuem total liberdade para oferecer brindes ou cupons de desconto, elas são dependentes da decisão da montadora de ofertar esses itens. A oferta desses itens é variada, no caso da CAV1 ocorre em campanhas promocionais, e na CAV5 a montadora "tem programas de pontuaçáa”. As concessionárias que decidem por essa concessão realizam para "modelos que náo vendem com tanta frequência", como no caso da CAV4, ou entáo em "negociaçóes caso a caso, na mesa do vendedor com o gerente [...] oferecemos brindes tanto para ajudar no fechamento do negócio, quanto no momento da entrega do veículo ao cliente" (CAV3).

Os planos de fidelidade são utilizados pelas empresas para criar e manter um relacionamento com os clientes, eles incentivam a lealdade do consumidor (LADEIRA; SANTINI, 2018). Não existem planos de fidelidade em todas as concessionárias entrevistadas, como é o caso da CAV4 e CAV2, que não fazem uso dessa estratégia. As demais variam suas formas de fidelizar o cliente, através de planos de financiamento que "ao final do pagamento das parcelas" são oferecidos benefícios aos clientes que se fidelizarem (CAV3). Também são oferecidos benefícios aos clientes que se mantiverem fiéis durante as revisóes (CAV1). Percebe-se que os planos de fidelidade fazem parte do pós-venda, ou seja, é uma estratégia de promoção que age após a venda concluída, de forma a manter o cliente próximo da empresa.

Quanto ao marketing direto, este não é realizado pela CAV3, de acordo com o gestor "dispomos de site, mas as compras são realizadas somente na concessionária”. As demais concessionárias utilizam do marketing direto como uma estratégia de promoção de vendas. Resultado semelhante ao estudo de Fonseca (2013), no qual o marketing direto era pouco utilizado pelas concessionárias, pois suas estratégias eram voltadas para o público geral, e não para um público individual.

Algumas datas comemorativas são mais exploradas pelo marketing das concessionárias de veículos, como o Natal (CAV1, CAV2, CAV3, CAV4, CAV5), Carnaval (CAV4), Páscoa (CAV4), Dia das Mães (CAV3, CAV4), Dia dos Pais (CAV4) e Black Friday (CAV1, CAV3). Essas campanhas são autorizadas pela concessionária no caso da CAV4, pela concessionária e pela montadora no caso da CAV3 e CAV5, e exclusivamente pela montadora no caso da CAV1 e CAV2. 
A palavra 'sonhos' é utilizada pelas concessionárias para desenvolver alguns de seus slogans. Outra ação utilizada por todas as concessionárias é o "comprou ganhou”. Essas estratégias são formuladas pela concessionária (CAV4), pela concessionária e montadora (CAV3, CAV5), ou, então, exclusivamente pela montadora (CAV1, CAV2).

Os gestores foram questionados se as ações de promoção de vendas eram realizadas para aumentar o consumo, lançar os novos produtos e estimular a experimentação. Todas as concessionárias utilizam-se dessas ações, o que já havia ficado notório nos outros questionamentos, que informaram que as promoçóes servem para alavancar vendas. A pesquisa desenvolvida por Fonseca (2013), em concessionárias Ford de Brasília/DF, demonstra que em uma das concessionárias as promoçôes não eram realizadas com o propósito da venda, mas com o propósito de atrair clientes para a empresa para que, lá, a venda seja promovida.

As estratégias de promoção de vendas são diversificadas; a concessionário CAV2 não se envolve com essas estratégias, elas são definidas exclusivamente pela montadora. A CAV1 utiliza "venda externa, ampla divulgação nas mídias sociais, venda por internet". A CAV4 divulga o "bônus da montadora”. Já a concessionária CAV3 expóe que essas estratégias são dependentes da época do ano e da disponibilidade de estoque. Segundo o entrevistado, "além disso, influencia muito a carta mensal de bônus que a montadora disponibiliza, são fatores essenciais para determinarmos o que será vinculado em mídia” (CAV3).

Cabe destacar aqui a explanação de Kotler (2000), quando informa que as empresas internacionais devem decidir qual a melhor forma que irão abordar suas estratégias de marketing, se padronizado em nível global, se com menores custos, ou se em nível local, com um marketing mais adaptado. Porém, por vezes esta escolha já é pré-definida pela empresa líder, neste caso a montadora, então a empresa filial não possui muita escolha a não ser trabalhar com o que lhe foi posto.

De todas as concessionárias entrevistadas, apenas a CAV2 não possui autonomia para delinear essas estratégias, as demais concessionárias possuem autonomia para tal, desde que alinhadas com as estratégias da montadora. Percebe-se que a autonomia para as estratégias de promoção segue as demais variáveis, as concessionárias podem definir essas estratégias, desde que estejam alinhadas com a montadora. Este fenômeno liga-se à governança, conforme explica Humphrey e Schmitz (2001, p.6),

a questáo da governança surge quando algumas empresas na cadeia trabalham segundo parâmetros estabelecidos por outras. Quando isso ocorre, pode ser necessário que as estruturas de governança transmitam informaçôes sobre parâmetros e promovam a obediência dos mesmos.

Pieritz (2007), baseado nos resultados de sua pesquisa, explica que as concessionárias apresentam certa dependência com a montadora, pois por mais que tenham liberdade nas suas decisóes, devem seguir as regras estabelecidas pela montadora. Resultado semelhante ao identificado por Hermes e Sausen (2019) em concessionárias do Rio Grande do Sul, na qual, apesar da dependência às montadoras, as concessionárias apresentaram a capacidade de poder desenvolver promoçóes direcionadas ao público-alvo da região. Assim, como exposto pelo gestor da CAV3 quando explica que existem as promoçóes de nível nacional, dominadas pelas montadoras, e aquelas de nível regional, em que as concessionárias possuem certa autonomia.

Por fim, foi questionado aos gestores se eles utilizam algum software, sistema, ferramenta para registro de seus clientes. O questionamento foi levantado, pois Kotler (2000) salienta que existe a ênfase 
na efetivação da venda, mas não na construção de relacionamentos. Kotler e Keller (2012) destacam que o marketing se preocupa cada vez mais em desenvolver relacionamento com todos que possam impactar no sucesso do marketing da empresa.

A colocação do gestor da concessionária CAV3 expressa como a empresa se preocupa com a construção de um relacionamento duradouro com seus clientes: "nosso banco de dados é nosso maior patrimônio e evidencia nosso interesse em fazer contatos frequentes para fidelizar nosso cliente e garantir que ele esteja satisfeito com nossos produtos e atendimento". Preocupação também identificada por Fonseca (2013), pois as concessionárias também dispunham de um cadastro de clientes que era utilizado para verificação da satisfação deles e, assim, criar um relacionamento. Os sistemas que são utilizados são CRM (Customer Relationship Management) (CAV4, CAV5), sistema NBS (CAV1).

\section{CONCLUSÃO}

O processo de globalização trouxe mudanças para todos os países, e com ela o desenvolvimento de Cadeias Globais de Valor, para a possibilidade de fragmentação da produção global. Com isso, as estruturas de poder centralizaram-se, em alguns casos, em países centrais, que detêm maior conhecimento do processo tecnológico. Mesmo assim, caso a nação saiba tirar proveito da sua inserção, os países que estão inseridos em uma CGV possuem benefícios valiosos, como o desenvolvimento industrial e econômico. Mas não é tarefa fácil e nem automática a entrada de países a uma CGV é preciso atender a algumas exigências antes. Autores revelam que a inserção em uma CGV auxilia no upgrading da economia da nação.

Através de pesquisa qualitativa com o uso do estudo de caso, foi possível verificar os objetivos propostos neste trabalho. Para isso, foram realizadas entrevistas semiestruturadas com gestores de cinco concessionárias autorizadas de diferentes montadoras mundiais. Após a análise dos dados coletados, foi possível chegar a conclusóes que serão apresentadas nesta seção.

As características demográficas dos entrevistados se dividem em gestores homens e mulheres, não há uma predominância significativa quanto ao gênero. A média de atuação na concessionária é de 10 anos, variando de 2 a 10 anos. Quatro dos entrevistados possuem ensino médio completo, sem formação superior concluída, o que mostra que eles estão inseridos na prática da atividade, porém desconhecem o que a academia tende a apresentar. Apenas um possui o ensino superior completo. A faixa etária dos respondentes vai de 26 a 60 anos de idade, o que não quer dizer que jovens não atuem nessa área de gestão, uma vez que pode o gestor ter ingressado com menos de 26 anos na empresa e admitido na vaga de gestáo.

O preço discriminatório e o geográfico são utilizados como estratégia por algumas das concessionárias. Com eles as empresas podem utilizar a estratégia de preço como forma para a venda de seus produtos, apesar de não ser um item do composto promoção de vendas, considera-se importante para a comercialização de produtos ou serviços.

As quatro concessionárias oferecem descontos como estratégia de precificação, que é uma boa estratégia para um segmento de clientes, porém há outros que prezam pela qualidade do serviço e do atendimento. Portanto, Kotler e Keller (2012) expóem que é preciso cautela quanto a essa estratégia, pois ao mesmo tempo que pode atrair o cliente, pode também afastá-lo e reduzir a força da marca. 
A realização de promoçóes de venda monetária e não monetária é feita por todas as concessionárias pesquisadas. Percebeu-se também que o tipo de carro que é ofertado, se popular ou de luxo, pode influenciar o canal de mídia em que a propaganda é apresentada, e também na estratégia de promoção de vendas.

As concessionárias pesquisadas utilizam diversos canais para realização das promoçôes de vendas, dentre eles as redes sociais e o site. Todas as concessionárias possuem apenas página na rede social Facebook, algumas destas páginas são do grupo e não própria da concessionária, assim como o caso do site. Cabe destacar que as promoçóes de vendas realizadas nas redes sociais não possuem uma visão de vendas em curto prazo, o objetivo destas é o fortalecimento da imagem da marca e o seu relacionamento com os consumidores (LADEIRA; SANTINI, 2018).

A estratégia de plano fidelidade não é utilizada por todas as empresas, apenas a CAV3, CAV4 e CAV5 fazem uso desta estratégia de forma variada, seja através de planos de financiamento, seja através de revisôes, por exemplo. A exploração de datas comemorativas também é uma das estratégias utilizadas por algumas empresas, datas como Natal, Carnaval, Black Friday.

Com a realização deste estudo foi possível perceber que as concessionárias autorizadas de automóveis utilizam da promoção de vendas com o propósito de alavancar suas vendas, reduzir seu estoque e girar produtos que estão parados. Quanto à autoridade para desenvolver e deliberar as estratégias de vendas nas concessionárias, são poucas as tarefas que os gestores destacaram como de autoridade exclusiva da concessionária. Geralmente a concessionária tem a liberdade na tomada de decisão, porém é preciso que as estratégias e a decisão estejam de acordo com as diretrizes da montadora. O caso da CAV2 é o único em que o gestor afirma que as decisóes são de responsabilidade da montadora, e a concessionária apenas segue o que foi estabelecido e repassado pela montadora.

Portanto, percebe-se que esse elo da cadeia de valor não possui total autonomia para tomar suas decisôes, quando é dito que a concessionária é responsável pela tomada de decisão, esta é subordinada às diretrizes colocadas pela montadora (empresa líder). Portanto, mesmo com a internacionalizaçáo de países em desenvolvimento, como o Brasil, ainda existe a concentração e a centralização do capital nas grandes corporaçóes globais, fato que se liga aos apontamentos de Hiratuka e Sarti (2017). Isso mostra que mesmo com a inserção de novos entrantes nas CGVs, o capital ainda assim está concentrado nas grandes empresas detentoras do poder.

Este estudo colaborou com a disseminaçáo dos estudos sobre cadeia global de valor, proporcionando a compreensão de como ocorre a estratégia de promoçáo de vendas nas concessionárias autorizadas de automóveis. O que de fato é relevante para a literatura, pois revela melhor como funciona a cadeia global de valor da indústria automobilística. O artigo utiliza a análise de redes sociais e site das concessionárias para verificação da promoção de vendas nesse canal, o que é um avanço nas análises da literatura relacionada à promoção de vendas.

Como toda pesquisa acadêmica e científica, essa também apresenta limitaçóes, sendo a principal a recusa de alguns dos gestores de concessionárias em concederem entrevistas, seja por falta de interesse em colaborar com a investigaçáo, seja pela falta de tempo/agenda para responder as questóes. No entanto, apesar da limitação supracitada, os dados aqui coletados não comprometeram os resultados, pelo contrário, mostraram-se suficientes para compor uma análise robusta e fiel à realidade apresentada. Ainda nesse sentido, visualizando possibilidades de estudos futuros, sugere-se que novas pesquisas sejam realizadas 
com concessionárias de outras regióes do Brasil, sob outras características e abordagens, podendo-se realiza-las sob a ótica dos estudos quantitativos, qualitativos ou mistos. Podendo, também, utilizar os outros componentes do mix de marketing para a realização de tais pesquisas.

\section{AGRADECIMENTO}

O presente trabalho foi realizado com apoio da Coordenação de Aperfeiçoamento de Pessoal de Nível Superior - Brasil (CAPES) - Código de Financiamento 001.

\section{REFERÊNCIAS}

ALMEIDA, M. A. G.; LINS, H. N.; CATELA, E. Y. S. Cadeias Globais de Valor, Inovaçáo e Upgrading. Estudo sobre empresas industriais argentinas com base em microdados. Revista de Economia Contemporânea, v. 24, n. 3, Dec., 2020.

AMA - AMERICAN MARKETING ASSOCIATION. What is Marketing? 2017. Disponível em: https://www.ama.org/the-definition-of-marketing-what-is-marketing/. Acesso em 12 dez. 2019.

\section{ANFAVEA - ASSOCIAÇÃO NACIONAL DOS FABRICANTES DE VEÍCULOS}

AUTOMOTORES. Anuário da Indústria Automobilística Brasileira 2019. São Paulo, jan. 2019.

Disponível em: http://www.virapagina.com.br/anfavea2019/2. Acesso em 11 dez. 2019.

ARAÚJO, C. G.; DIEGUES, A. C. Brasil e China: Os descaminhos da inserção nas cadeias globais de valor. Textos para Discussão, Instituto de Economia da Unicamp, n. 406, mar., 2021.

BIAZUS, G. Estudo das estratégias de marketing da empresa Tussi Veículos Ltda. 2015. Trabalho de Conclusão de Curso (Bacharel em Administração), Universidade Federal da Fronteira Sul, 2015.

CAMPOS, H. P. A Inserção da Indústria Catarinense nas Cadeias Globais de Valor. 2019.

Dissertação (mestrado em economia). Programa de Pós-Graduação em Economia, Universidade Federal de Santa Catarina, 2019.

CARVALHO, E. G. Globalização e estratégias competitivas na indústria automobilística: uma abordagem a partir das principais montadoras instaladas no Brasil. Gestáo \& Produçáo, p. 121-133, 2005.

COSTA, R. M.; HENKIN, H. Estratégias competitivas e desempenho da indústria automobilística no Brasil. Economia e Sociedade, v. 25, n. 2, p. 457-487, 2016.

CRESWELL, J. W. Métodos Qualitativos. In: Projeto de pesquisa métodos qualitativo, quantitativo e misto. (tradução Magda Lopes) 3 ed. Porto Alegre: Artmed, p. 206-237, 2010.

FLICK, U. Pesquisa qualitativa online: a utilização da internet (cap. 20); Documentação de dados (cap. 22); Interpretação do texto: uma visão geral (cap. 27). In: Introduçáo à pesquisa qualitativa. (tradução Joice Elias Costa). 3 ed. Porto Alegre: Artmed, cap. 20, 22, 27, 2009. 
FLORES, M. R. O pós-venda como ferramenta para fidelização de clientes. 2018. Dissertação (Mestrado em Gestấo). Instituto Superior de Gestão, Business \& Economics School, Lisboa, 2018.

FONSECA, A. V. A. N. Estratégias de marketing: mix de marketing e comunicação nos distribuidores Ford de Brasília. 2013. Monografia (Graduação) - Faculdade de Tecnologia e Ciências Sociais Aplicadas - FATECS, Centro Universitário de Brasília, Brasília, 2013.

GEREFFI, G. A commodity chains framework for analyzing global industries. Durham: Duke University, 1999.

GEREFFI, G.; FERNANDEZ-STARK, K. Global Value Chain Analysis: A Primer. Center on Globalization, Governance and Competitiveness, 2011.

GOI, C. L. A review of marketing mix: 4Ps or more? International journal of marketing studies, v. 1, n. 1, p. 2-15, 2009.

HERMES, L. C. R.; SAUSEN, J. O. Práticas de Trade Marketing como vantagem competitiva para produtos duráveis: um estudo de caso em concessionárias de veículos. Gestáo \& Planejamento-G\&P, v. 20, p. 239-254, jan./dez., 2019.

HIRATUKA, C.; SARTI, F. Transformaçóes na estrutura produtiva global, desindustrialização e desenvolvimento industrial no Brasil. Revista de Economia Política, v. 37, n. 1, p. 189-207, 2017.

HONORATO, G. Conhecendo o Marketing. Barueri: Manole, 2004.

HOOLEY, G. J.; PIERCY, N.; NICOULAUD, B. Estratégia de marketing e posicionamento competitivo. 4. ed. São Paulo: Pearson Prentice Hall, 2011.

HUMPHREY, J.; SCHMITZ, H. Governance and upgrading: Linking industrial cluster and global value chain research, IDS Working Paper No. 120, Institute of Development Studies, University of Sussex, Brighton, 2001.

IEDI - O Descompasso Brasileiro Entre Investimento Externo Direto e Participação nas Cadeias Globais de Valor. Edição 597, 2013.

IEDI - Brasil nas Cadeias de Valor: Avanços Insuficientes. Edição 734, 2016.

KOTLER, P. Administração de marketing: análise, planejamento, implementação e controle. 5. ed. São Paulo: Atlas, 1998.

KOTLER, P. Administração de Marketing. (Tradução Bazán Tecnologia e Lingüística). 10 ed. São Paulo: Pearson, 2000.

KOTLER, P.; KELLER, K. L. Administração de marketing. (Tradução Sônia Midori Yamamoto). 14. ed. São Paulo: Pearson Education do Brasil, 2012.

LADEIRA, W.; SANTINI, F. Merchandising e promoçáo de vendas: como os conceitos modernos estão sendo aplicados no varejo físico e na internet. São Paulo: Atlas, 2018. 
LIMA, U. M. A Cadeia Global de Valor da indústria automobilística: dinâmica de produção e comércio exterior. Boletim de Economia e Política Internacional, n. 17, maio/ago, 2014.

MESQUITA, D. L.; BORGES, A. F.; SANTOS, A. C.; SUGANO, J. Y. Aspectos Institucionais da Inovação: uma análise acerca dos Regimes Automotivos Brasileiros de 1995 e 2012. In: Congresso Latino-Iberoanericana de Gestão de Tecnologia, 15, Portugal. Anais [...] Portugal, 2013. Disponível em: http://www.altec2013.org/programme_pdf/671.pdf. Acesso em 10 dez. 2019.

NEPOMUCENO, D.; REIS, I.; BERNARDO, M. B.; FONSECA, G. Análise sobre as açôes estratégicas adotadas em uma concessionária para superar a crise. In: Congresso Nacional de Excelência em Gestão, 22, 2016. Anais [...] Rio de Janeiro: FIRJAN, 2016.

PIERITZ, O. Concessionárias de Automóveis: estratégias competitivas e relaçôes de dependência com montadoras. Revista de Negócios, v. 8, n. 4, p. 1-15, 2007.

REIS, C. F. B.; ALMEIDA, J. S. G. A inserção do Brasil nas cadeias globais de valor comparativamente aos BRIICS. Campinas: Instituto de Economia, UNICAMP, 2014.

STRAUSS, A. L.; CORBIN, J. Pesquisa Qualitativa: Técnicas e procedimentos para o desenvolvimento de teoria fundamentada. Artmed, 2008.

TIMMER, M. P.; ERUMBAN, A. A.; LOS, B.; STEHRER, R.; VRIES, G. J. Slicing up global value chains. Journal of economic perspectives, v. 28, n. 2, p. 99-118, 2014.

TORRES, R. L. A indústria automobilística brasileira: uma análise da cadeia de valor. 2011.

Dissertação (Mestre em economia). Programa de Pós-Graduação em Economia, Universidade Federal de Santa Catarina, Florianópolis, 2011.

TORRES, R. L.; CARIO, S. A. F. A governança da cadeia global de valor na indústria automobilística: um estudo de caso. Revista Econômica, v. 14, n. 1, p. 73-91, 2012.

TORRES, U. P. P.; MARTINS, H. C. Análise estratégica das áreas de marketing e finanças no processo de formação e manutenção dos preços: o caso da montadora Fiat Automóveis SA. Revista Eletrônica de Ciência Administrativa, v. 5, n. 1, p. 1-15, 2006.

WALLERSTEIN, E. The Capitalist World Economy. Cambridge University Press, 1979. Disponível em: https://books.google.com.br/books/about/The_Capitalist_World_Economy. html?id=5GppqmU13pIC\&redir_esc=y. Acesso em 15 nov. 2019.

YIN, R. K. Estudo de Caso: Planejamento e Métodos. 5a ed., Porto Alegre/RS: Bookman, 2015.

ZHANG, L.; SCHIMANSKI, S. Cadeias Globais de Valor e os Países em Desenvolvimento. Boletim de Economia e Política Internacional - BEPI, Instituto de Pesquisa Econômica Aplicada - IPEA, n. 18, set./dez., 2014. 